\title{
Factors affecting the Academic Performance of university students residing in Student Housing Facility
}

\author{
Shazia Hasan \\ University of central Punjab, Lahore Pakistan
}

Mehreen Fatima

COMSATS Institute of Information Technology, Lahore Pakistan

\section{Introduction}

In theory and literature, it is stated that self-efficacy affects the individual in how they feel, think or act (Bandura, 1995). As far as "feeling" is concerned, low selfefficacy is related to anxiety and helplessness. Individuals possessing low selfefficcy have tendency to access pessimistic thoughts about themselves in terms of accomplishments and personal growth and development. For "thinking", sense of being competent facilitates performance in a variety of ways including acadcmic achievement (Schwarzer et al., 1997).

\section{Stress}

Stress is a defined as a "state of psychological arousal that results when external demands tax or exceed a person's adaptive abilities" (Zajacova et al., 2005).

Many studies have been conducted to investigate the association between stress and academic performance. According to Zajacova et al. (2005), stress and selfefficacy are closely associated concepts. In their cognitive model of stress, Lazarus and Folk man (1984) stated that among other personal beliefs, self-efficacy is very crucial to evaluate environmental demands. Physiological arousal state related to stress offer information that affects judgment of self-efficacy. Therefore stress can lower the self-efficacy judgment of students (Zajacova et al., 2005). Beedie and Kennedy (2002) mentioned in their study that social support has buffering effects on stress level.

Ruprai et al. (2012) mentioned that among many other factors, hostel problems, including hostel food, friends and home sickness, are the most significant source of stress for students. Stress coming from any source can have negative impacts on 
health, academic performance and personal adjustment of students (Nelson et al., 2001). World Health Organization has projected that by the year 2020, mental diseases, along with stress, will become $2^{\text {nd }}$ leading source of disabilities (WHO, 2004).

The main objectives of this study are to:

1. Identify students' satisfaction with their residence in hostels.

2. Find the effect of student's satisfaction with hostel on their stress level, self-esteem, self-efficacy and academic performance

3. Compare data of students from different semesters to identify the factors affecting students academic performance

A model (Figure 1) is constructed on which this study is based.

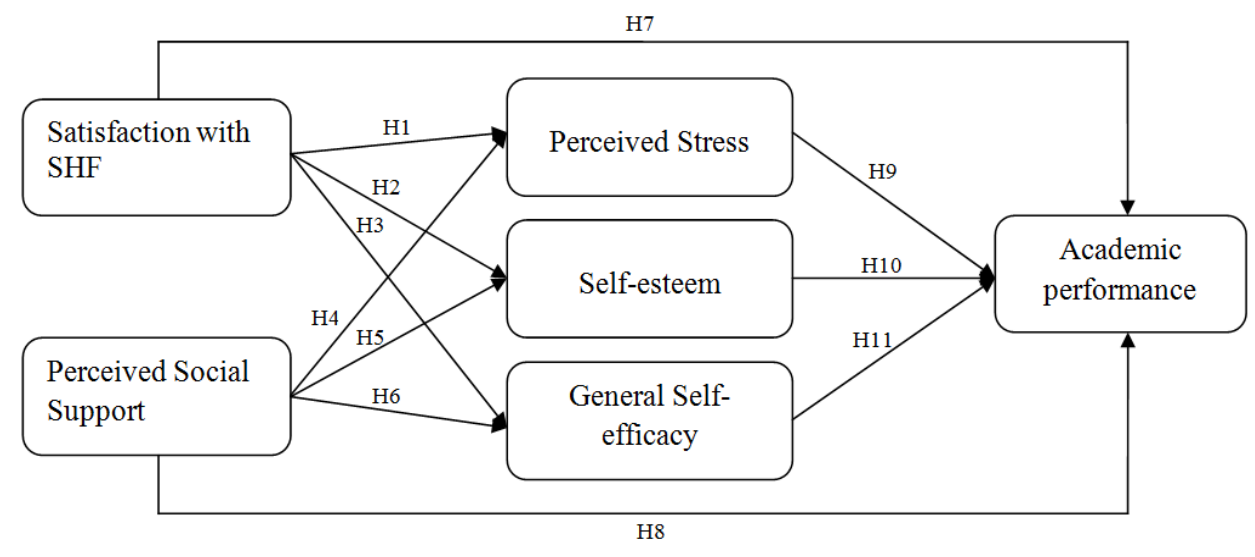

Figure 1

\section{Hypotheses}

This study has developed following hypotheses from the model (Figure 1).

Hypothesis 1: Satisfaction with student housing facility is negatively related to perceived stress.

Hypothesis 2: Satisfaction with student housing facility is positively related to self-esteem.

Hypothesis 3: Satisfaction with student housing facility is positively related to general self-efficacy.

Hypothesis 4: Perceived social support is negatively related to perceived stress.

Hypothesis 5: Perceived social support is positively related to self-esteem.

Hypothesis 6: Perceived social support is positively related to general selfefficacy. 
Hypothesis 7: Satisfaction with student housing facility is positively related to academic performance of students.

Hypothesis 8: Perceived social support is positively related to academic performance of students.

Hypothesis 9: Perceived stress is negatively related to academic performance of students.

Hypothesis 10: Self-esteem is positively related to academic performance of students.

Hypothesis 11: General self-efficacy is positively related to academic performance of students.

Hypothesis 12: Perceived stress, self-esteem and general self-efficacy partially mediate the relationship between academic performance and satisfaction with housing facility and perceived social support.

\section{Methodology}

This study is based on primary data analysis and cross-sectional survey of data collected from the resident students of Fatima Jinnah Girls Hostel, CIIT Lahore, Pakistan. The targeted population consists of all the girls of bachelor programs residing in Fatima Jinnah Girls Hostel of CIIT Lahore. A sample of 200 students is selected through systematic random sampling. Data is collected through questionnaires. Age is taken as a demographic variable in this study. Gender is frequently used in many studies (Fay, 1981; Alkandari, 2007) to measure the results in comparative manner. But, in this study, respondents are only females.

Measures of variables: Different measures are used to devise the questionnaire.

Satisfaction: Satisfaction with student housing facility is taken as one of the independent variables in this study. It is measured by adopting the questionnaire used by Najib and Abidin (2011) in their study. It consists of forty six items with four response choices: Strongly dissatisfied (1), Dissatisfied (2), Satisfied (3) and Strongly satisfied (4). The highest score on the scale shows highest level of satisfaction with the housing faciliy provided by the university.

Perceived Social Support: It is also taken as an independent variable to predict the outcome variables. It is measured with the scale developed for it by Zimet et al. (1988). It consists of twelve items with seven response choices: Very Strongly Disagree (1), Strongly Disagree (2), Mildly Disagree (3), Neutral (4), Mildly Agree (5), Strongly Agree (6) and Very Strongly Agree (7). The highest score on the scale shows the highest level of perceived social support that a person possess. 
Perceived Stress: Perceived stress is used as an outcome variable as well as an independent variable for academic performance of students. It is measured by the scale developed by Cohen et al. (1983). It measures stress level the way it is perceived by the repondents. It consists of four items with five response choices: Never (0), Almost never (1), Sometimes (2), Fiarly often (3), Very often (4). The highest score on the scale shows higher stress level.

Self-esteem: It is one of the dependent variables of the study but also used as a predictor to predict students' academic performance. Self-esteem is measured through the rozenberg self-esteem scale (Rosenberg, 1965). It consists of ten items with four response choices: Strongly disagree (0), Disagree (1), Agree (2) and Strongly agree (3). The highest score on the scale shows higher self-esteem level possessed by the student.

Perceived Self-efficacy: This variable is taken as a dependent variable in this paper. But it also used as an independent variable to predict students' academic performance. This study has utilized the self-efficacy scale developed by Schwarzer and Jerusalem (1995). It consists of ten items with four response choices: Not at all true (1), Hardly true (2), Moderately true (3) and Exactly true (4). The highest score on this scale displays the higher self confidence that a student has in her capabilities.

Academic performamnce: In their study, Zajacova et al., (2005), examine academic performance by three measures. These three measures include grades of high school, cumulative result of first year and status in third semester. Here we have incorporated few changes. Instead of cumulative result of first year, current CGPAs of the students are included and grades of previous degree are also recorded in order to find their impact on current performance.

\section{Data analysis}

Data is analyzed using SPSS. Descriptive statistics is applied on all the variables. Multivariate Regression is run for three models which are given as Equation (1), Equation (2) and Equation (3). Here Perceived stress is abbreviated as PSt; Satisfaction as S; Perceived social support as PSS; Self-esteem as SE and general self-efficacy as GSE.

$$
\begin{array}{ll}
\text { Model -1 } & \text { PSt }=\alpha_{1}+\beta_{1} \text { Age }+\beta_{2} \mathrm{~S}+\beta_{3} \text { PSS }+\varepsilon \ldots . . \text { Equation }(1) \\
\text { Model -2 } & \mathrm{SE}=\alpha_{2}+\beta_{1} \text { Age }+\beta_{2} \mathrm{~S}+\beta_{3} \mathrm{PSS}+\varepsilon \ldots . . \text { Equation }(2) \\
\text { Model -3 } & \mathrm{GSE}=\alpha_{3}+\beta_{1} \text { Age }+\beta_{2} \mathrm{~S}+\beta_{3} \mathrm{PSS}+\varepsilon \ldots . . \text { Equation }(3)
\end{array}
$$

Linear regression is run for four models to find out the impact of different variables on academic performance of students. These four models are given as Equation (4), 
Equation (5), Equation (6), and Equation (7). Here current semester of student is taken as Se; Previous academic performance is taken as PAP, staying with same roommates is taken as SM and get along with roommates is taken as GR.

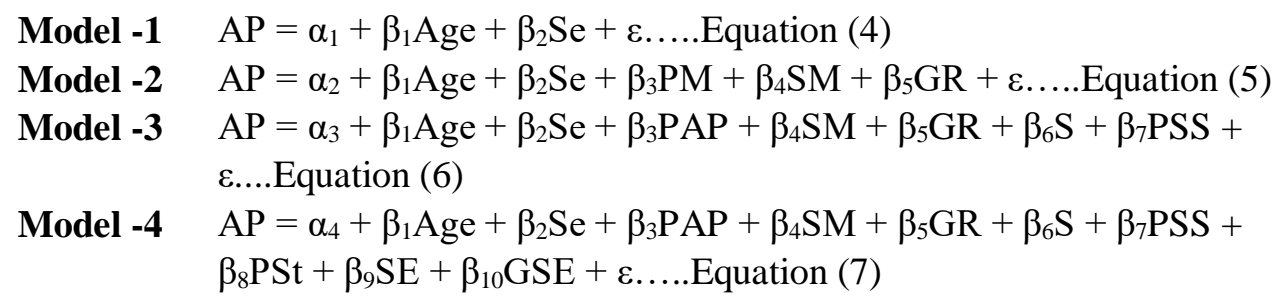

\section{Results and discussion}

Analysis is done with the help of SPSS. Descriptive statistics is applied on all the variables. Spearmen Correlation, Multivariate Regression and Linear Regression are used to test the hypotheses. Overall descriptive statistics of the variables are given in Table 1. Two groups are formulated for eight semesters. First four semesters are included in Group 1 and last four semesters are included in Group 2. A semester wise analysis is also done to find out the mean values for each semester. These mean values show that with each semester, comes a change in students' experience of housing facility. These changes come due to change in complexity of study subjects; change in number of friends; change in certain residence rules or due to living with same roommates for a longer time. Significant change can be seen in staying with same roommates with each semester.

Overall mean value for staying with same roommates shows that students are living with same roommates for over three semesters on the average. Difference is quite visible in both groups and in semester wise analysis. The higher the semester the higher is the mean. This depicts that students find good friends in housing facility and prefer to stay with them overtime. Getting along with roommates is quite closer to 1 overall and also in comparison analysis for almost all semesters. This might be due to the reason that most of the students share room with 1 or 2 persons at home. This helps in getting adjusted to residence environment where students have to share room with other students.

Loyalty behavior of students is measured through three questions (Table 1). Most of the students show their willingness that they will stay in this housing facility till the end of their study in this university. For this, mean values are very close to 2 . It is also found in literature that satisfaction generated from housing facility of university will affect students' decision to stay in the same facility for next 
semesters or till the end of study (Foubert et al., 1998; Najib \& Abidin, 2011). However, results for living in this housing facility again are displaying quite low willingness to stay. Overall mean value (.49) is not good enough to show their willingness to stay in this facility again. Surprisingly, students do not want to live in the housing facility again but they are ready to recommend this facility to their friends. Overall as well as all comparison means are high for recommending this housing facility to their friends as compare to their own willingness to stay here again. Possible explanation could be that this university is quite far away from city and housing facility is inside the university premises so it is quite difficult for girls to reach university from some other housing facilities. Taking this as context, students believe that this facility is the better option for girls' students. Apart from this, when a student is satisfied with his or her experience of residing in the housing facility, he or she will share this experience with others (Pizam \& Ellis, 1999).

Students' satisfaction and overall residence experience changes with each semester. According to Rodger and Johnson (2005), in start students felt themselves as less a part of their surrounding as compare to those students who are living there for longer period of time. Mean value of satisfaction is 2.61 overall while for two groups it is 2.63 and 2.6 respectively. This shows that students are more inclined towards being satisfied rather than being dissatisfied from the housing facility and no visible difference exists between the two groups. On the other hand, mean of satisfaction level for different semesters is different. Satisfaction level varies in different semesters but this difference is minor and in almost all semesters students remain more inclined towards being satisfied. Students are found to be more satisfied with security and study environment of housing facility and comparatively less satisfied with facilities, cleanliness and privacy in rooms.

Overall perceived social support shows good results (5.49). Comparison of the two groups shows difference in results, Group 1 (5.38) and Group 2 (5.60), but difference is not much visible. Group 1 shows more inclination towards mildly agree that they have social support while Group 2 is more inclined towards being strongly agreed that they possess social support. Difference is much visible in semester wise comparison of means. Mean for social support increases with each semester and then decreases again till end. Possible explanation could be that students get involve with friends and this involvement increases with semester. Later on, in end semesters, friends get filtered and only more important friends remain in circle. Perceived social support is highest from family, less form friends and much lesser from others. This trend is prevalent in group comparison as well as in semester wise comparison. This is natural for a person to perceive more support from family than from friends and than from anyone else. Mean value of perceived 
stress (2.36) shows that students of housing facility are sometimes in stress and do not remain in stress often. Results for two groups are quite similar. Students of Groups 1 (2.41) are more stressed as compare to students of Group 2 (2.31) but this difference is negligible. In semester wise comparison, it is evident that stress is high in starting semesters which decreases overtime but again increases till the end of semesters. It might be due to the reason that students are more stressed out due to homesickness or maladjustment in boarding in start which releases over time but is replaced by academic stress in end semesters. In literature, stress is found to get augmented as students move from high school to college (Towbes \& Cohen, 1996).

Mean value of self-esteem (1.80) displays that overall students are more inclined towards having self-esteem. Two groups also show almost the same level of selfesteem. In semester wise comparison, self-esteem level is highest for students of first semester (2.11) which decreases later on and keeps on changing in different semesters but same level is not regained as of first semester. This is because of the rules of housing facility which are supposed to be followed. This makes a person as a follower which decreases his or her self-esteem. Rules of housing facilities affect highly as one has to live there for 24 hours a day and seven days a week unlike office or educational institute where one has to spend only few hours. General selfefficacy is almost same overall as well as for the two groups (Table 1). But semester wise comparison shows that self-efficacy is higher in first semester which drops in next semesters. As difference is not very visible therefore it could be said that there is no significant build up of self-efficacy after living in student housing facility.

According to literature, students living upstairs feel that their rooms are more spacious and therefore they are more satisfied with housing facility (Kaya and Erkip, 2001). But our results show much less difference (Table 2). Difference exists for all variables but it is not much visible. For perceived stress, students living downstairs are more stressed as compare to those living upstairs but difference is negligible. As there is no difference of satisfaction for students regarding the housing facility, therefore all other variables which are linked to satisfaction also show little difference. One possible reason could be that in the concerned housing facility, students are shuffled from upstairs to downstairs and vice versa in different semesters. This shuffling reduces the effects of living upstairs or downstairs which is more evident when student is living in a certain room for a longer period of time. 


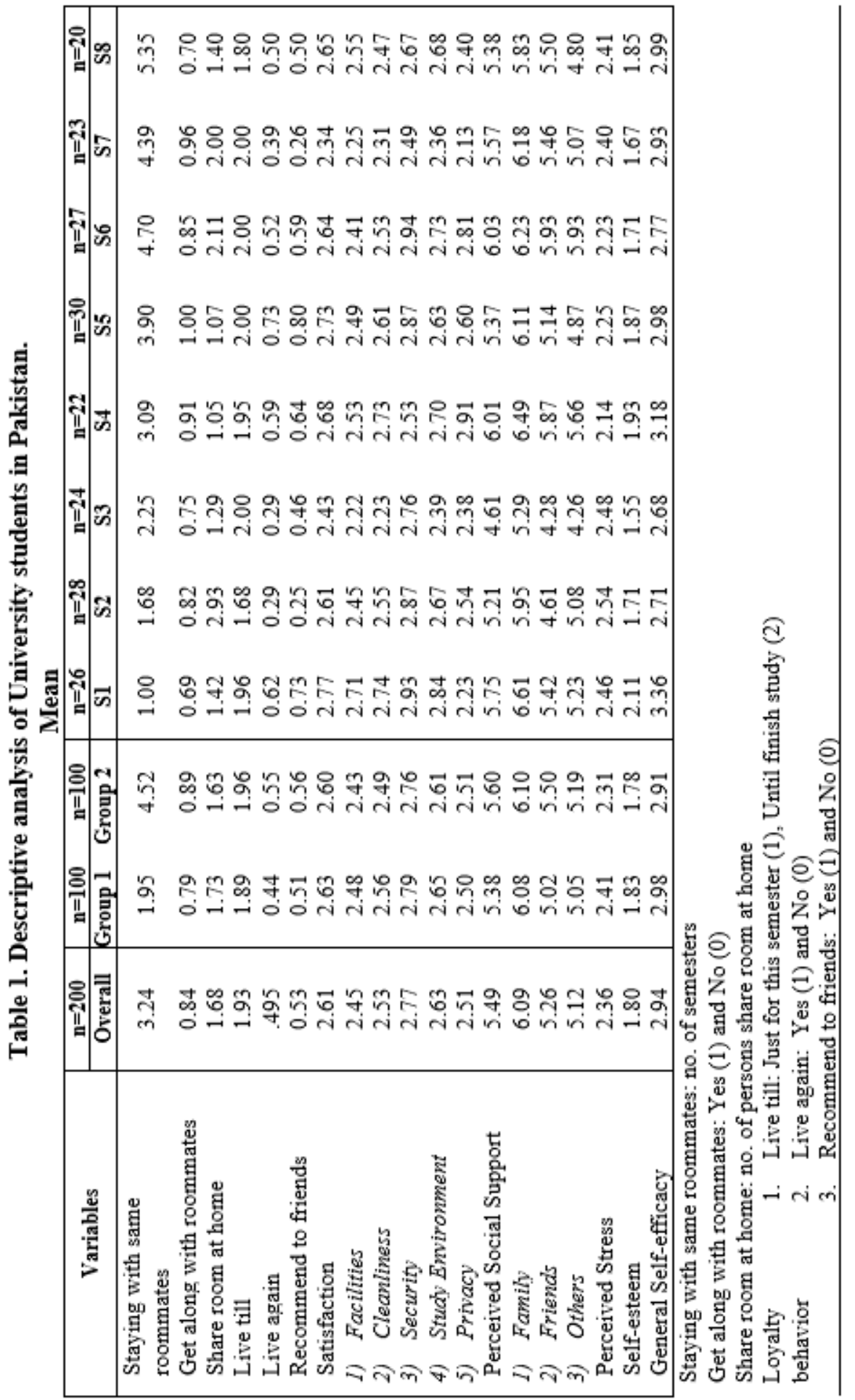


Table 2. Descriptive analysis on the basis of floor level

\begin{tabular}{lcc}
\multicolumn{2}{c}{ Mean } & \\
\hline & Upstairs & Downstairs \\
\hline Satisfaction & 2.60 & 2.60 \\
Perceived Social Support & 5.59 & 5.49 \\
Perceived Stress & 2.45 & 2.50 \\
Self-esteem & 1.92 & 1.86 \\
General Self-efficacy & 3.15 & 2.96 \\
\hline
\end{tabular}

Spearman correlation is applied on variables which gives us the correlation between different variables when data is non-normal. Table 3 shows that there exists significant correlation between some variables but no strong positive or negative correlation is found. Satisfaction with the housing facility is having significant correlation with self-esteem and general self-efficacy. Visible and highly significant correlation is found between self-esteem and perceived social support (.320). These two variables are positively associated with each other although not very strongly associated but there exists a weak association. General self-efficacy and perceived social support also shows visible highly significant positive correlation (.353). General self-efficacy also shows significant positive correlation with perceived stress (.175) and self-esteem (.317). This shows that general self-efficacy is positively correlated with perceived social support, perceived stress and self-esteem.

\begin{tabular}{|c|c|c|c|c|c|}
\hline \multicolumn{6}{|c|}{ Table 3: Spearman Correlation } \\
\hline & Satisfaction & $\begin{array}{l}\text { Perceived } \\
\text { Social } \\
\text { Support }\end{array}$ & $\begin{array}{l}\text { Perceived } \\
\text { Stress }\end{array}$ & $\begin{array}{c}\text { Self- } \\
\text { esteem }\end{array}$ & $\begin{array}{c}\text { General } \\
\text { Self- } \\
\text { efficacy }\end{array}$ \\
\hline Satisfaction & 1.000 & & & & \\
\hline $\begin{array}{l}\text { Perceived Social } \\
\text { Support }\end{array}$ & .032 & 1.000 & & & \\
\hline Perceived Stress & -.081 & $.170^{*}$ & 1.000 & & \\
\hline Self-esteem & $.156^{*}$ & $.320^{* *}$ & $.149^{*}$ & 1.000 & \\
\hline $\begin{array}{l}\text { General Self- } \\
\text { efficacy }\end{array}$ & $-.201^{* *}$ & $.353^{* *}$ & $.175^{*}$ & $.317^{* *}$ & 1.000 \\
\hline $\begin{array}{l}* \text {. Correlation is } \\
* * \text {. Correlation is }\end{array}$ & $\begin{array}{l}\text { cant at the } 0.0 \\
\text { icant at the } 0 \text {. }\end{array}$ & $\begin{array}{l}\text { level (2-tail } \\
1 \text { level (2-ta }\end{array}$ & $\begin{array}{l}\text { d). } \\
\text { ed). }\end{array}$ & & \\
\hline
\end{tabular}

Multivariate Regression is applied on independent variables to find out their impact on dependent variables. Linear regression can be run for each dependent variable separately but multivariate test performs an additional test to check the overall significance of the model. Table 4 contains Wilks' Lambda which tells the overall 
significance of the model. Values of Wilks' Lambda display that all the predictors are overall significant for the models.

For perceived stress (Table 4), only perceived social support is significant. It rejects Hypothesis 1 which states that satisfaction with student housing facility is negatively related to perceived stress. Beta coefficient of perceived social support shows that one unit increase in perceived social support will increase stress by .084. It rejects Hypothesis 4. It is contradictory to literaure which says that social support is negatively related to stress and therefore higher social support decreases stress (Dunn, 2001). As social support is positvely related to stress, this might be due to the reason that higher social support increases self-esteem and self-efficacy but increases stress as well because it increases the pressure to confrm to the group of friends that is different from high school level where one has to meet friends for a certain period of time. There is also an emerging evidence in literature that the extent to which a person perceive himself as supported is influenced by his needs and personal expectations (Collins \& Feeney, 2004) which might be different from what others offer as a support. Perceived stress is not found to be significant with satisfaction level. Possible reason could be that stress is caused by some other reasons which are not included in our study. Stress might come from homesickness, financial issues, study, and university problems or from some other problems.

Table 4:

Multivariate Regression

\begin{tabular}{lllrrrr}
\hline Models & $\begin{array}{c}\text { Dependent } \\
\text { Variables }\end{array}$ & Parameters & B & $\begin{array}{c}\text { Std. } \\
\text { Error }\end{array}$ & t & Sig. \\
\hline 1 & Perceived & Intercept & 1.781 & .749 & 2.377 & .018 \\
& Stress & Age & .015 & .032 & .481 & .631 \\
& & Satisfaction & -.069 & .116 & -.594 & .553 \\
& & Perceived & .084 & .041 & 2.049 & .042 \\
& & Social Support & & & & \\
\hline 2 & Self-esteem & Intercept & 1.375 & .443 & 3.106 & .002 \\
& & Age & -.047 & .019 & -2.513 & .013 \\
& & Satisfaction & .223 & .069 & 3.238 & .001 \\
& & Perceived & .145 & .024 & 6.024 & .000 \\
& & Social Support & & & & \\
\hline 3 & General Self- & Intercept & 3.930 & .680 & 5.780 & .000 \\
& efficacy & Age & -.063 & .029 & -2.193 & .029 \\
& & Satisfaction & -.341 & .106 & -3.226 & .001 \\
& & Perceived & .215 & .037 & 5.798 & .000 \\
& & Social Support & & & & \\
\hline
\end{tabular}




\begin{tabular}{lccc}
\hline \multicolumn{2}{l}{ Overall significance of models (Wilks' Lambda) } & & \\
\hline \multicolumn{1}{c}{ Effect } & Value & F & Sig. \\
\hline Intercept & .843 & 11.996 & .000 \\
Age & .955 & 3.022 & .031 \\
Satisfaction & .859 & 10.583 & .000 \\
Perceived Social Support & .787 & 17.389 & .000 \\
\hline
\end{tabular}

Linear regression is run taking academic performance of students as dependent variable (Table 5). For this purpose, four models are run to find out the partial mediating effect of perceived stress, self-esteem and general self-efficacy on academic performance.

Age is not significant for performance in any model. Semester is significant in all four models and its significance increases with each model. Beta co-efficient decreases with each model but this decrease is nominal. Therefore it can be safely said that the higher the semester, the lower is the performance of the student. Previous academic performance of students is significant for their current performance in all models. This displays that the higher the previous performance the higher will be current performance. This is also evident through literature that previous academic performance has the ability to predict the current academic performance (Daugherty \& Lane, 1999; Wolfe \& Johnson, 1995). Staying with same roommates is significant in last two models. But its significance decreases in last model as compare to the second last model which shows that it is mediated by the variables incorporated in the last model. Get along with the roommates is not significant in any model but its beta co-efficient increases with each model till the last model.

Table 5:

Linear Regression run for academic performance (dependent variable) of students residing in students' housing facility.

\begin{tabular}{lllll}
\hline & Model 1 & Model 2 & Model 3 & Model 4 \\
\hline (Constant) & 72.172 & 40.769 & 50.688 & 53.046 \\
Age & .367 & .799 & .784 & .594 \\
Semester (Se) & $-1.097^{* *}$ & $-1.616^{* * *}$ & $-1.520^{* * *}$ & $-1.378^{* * *}$ \\
$\begin{array}{l}\text { Previous Academic } \\
\text { Performance (PAP) }\end{array}$ & & $.313^{* * *}$ & $.288^{* * *}$ & $.302^{* * *}$ \\
$\begin{array}{l}\text { Staying with same roommates } \\
\text { (SM) }\end{array}$ & .716 & $.881 * *$ & $.819^{*}$ \\
Get along with roommates & & & \\
(GR) & -1.172 & .548 & 1.022 \\
Satisfaction (S) & & & \\
Perceived Social Support (PSS) & & & -400 & 1.330 \\
Perceived Stress (PSt) & & & & $-1.806^{* * *}$ \\
Self-esteem (SE) & & & .318 \\
General Self-efficacy (GSE) & & & $-3.335^{*}$ \\
\hline
\end{tabular}




\begin{tabular}{lllll}
\hline Durbin Watson & 1.814 & 1.749 & 1.729 & 1.707 \\
R Square & .049 & .109 & .167 & .184 \\
Adjusted R Square & .038 & .083 & .132 & .134 \\
ANOVA (sig) & .014 & .001 & .000 & .000 \\
\hline$* * * \mathrm{p}<0.01$ & & & & \\
$* * \mathrm{p}<0.05$ & & & & \\
$* \mathrm{p}<0.1$ & & & & \\
\hline
\end{tabular}

Hypothesis 7 is rejected as satisfaction is not significant for academic performance in any model. This might be due to the reason that satisfaction with housing facility does not affect performance of the students living in housing facility provided by the university. Regarding this, contradiction in found in literature where some studies found significant relationship between satisfaction with residence and academic performance (Centra \&Rock, 1983) while some other studies found moderate relationship (Pike, 1991) and still some other found no relationship between the two (Bean \& Bradley, 1986). Perceived social support is found to be highly significant $(\mathrm{p}<0.01)$ with performance of students in last two models. But its beta co-efficient is negative which shows that the higher the perceived social support the lower will be academic performance of students. This rejects Hypothesis 8 which states that perceived social support is positively related to academic performance of students. Possible explanation could be that the bigger the social circle, the higher the chances of getting involved in activities other than academic.

In model 4 (Table 5), three variables are incorporated. Perceived stress is found to be insignificant with academic performance of students. Hypothesis 9 is rejected and the reason behind is that stress is not found through academic stress. Therefore, it is found out that perceived stress do not affect academic performance as do the academic stress. Academic related stress is found to be significant with academic performance in many research studies (Pritchard \& Wilson, 2003; Struthers et al, 2000). Self-esteem is significant $(\mathrm{p}<0.1)$ with academic performance. But this significance is quite low. Beta coefficient shows that the higher the self-esteem the lower will be the academic performance. It rejects Hypothesis 10 which states that self-esteem is positively related to academic performance of students. This needs to be explored that how higher self-esteem leads to lower academic performance. Possible reason could be that higher self-esteem makes a person become less dependent on others which might reduces his chances of getting important information or study help.

General self-efficacy is not found to be significant with academic performance of students. This is due to the reason that self-efficacy is measured through general 
self-efficacy scale which has less association with academic achievement of students (Multon et al., 1991) is not found to be able to predict academic outcomes (Lindley \& Borgen, 2002). Therefore, Hypothesis 11 is rejected. As the incorporation of perceived stress, self-esteem and general self-efficacy in model 4 did not affect the results of satisfaction and perceived social support therefore Hypothesis 12 is also rejected. Perceived stress, self-esteem and general selfefficacy do not mediate the relationship between academic performance and satisfaction with housing facility and perceived social support.

\section{Conclusion}

In this study, the results demonstrate that students outer environment as well as their personal characteristics (age) affect their psychology which in turn affects the way they perceive their environment and the way they respond back to it. Variables included in the study show variation in their values with each semester. Dimensions of satisfaction show that satisfaction level is high in the start which decreases with time and then enhances again till the end semesters. Perceived stress and general self-efficacy also shows the same results. But perceived social support shows vice versa results. It is low in the start, gets higher till the mid semester and then decrease till the end semesters. Self-esteem is higher in the start and shows on and off increase and decrease but remain low till the end semester.

In general the students residing in the housing facility are satisfied but this satisfaction is higher for study environment and security provided by the facility as compare to the facilities and cleanliness. Study also shows that students' satisfaction with the housing facility of the university is significant for loyalty behavior of students which is also consistent with literature (Najib \& Abidin, 2011). But satisfaction is not found to be significant for academic performance of the students. This is contradictory with some studies (Centra \&Rock, 1983) but it is also consistent with some other studies which provided the same results (Bean \& Bradley, 1986). Perceived social support is found to be significant with performance in this study but it shows negative relationship with academic performance. These are quite interesting results and needs to be further explored. Further research can explore how higher social support can lead to lower academic performance. Further investigation will add more value to these results.

Few results in this study are in contradiction with literature. Perceived stress and general self-efficacy are not found to be significant with academic performance 
while self-esteem has negative relationship with academic performance. Possible explanation for these results could be that there exist many other factors which affects students' satisfaction such as gender, age, socio-economic status, religion (Amole, 2009), culture etc. These factors also affect students' psychology and the way they perceive their environment and people. Further research with the inclusion of these factors can add more worth to these results.

\section{Limitations of study}

This study has certain limitations. Only one housing facility is taken as our population and respondents of the study are females only which limits the possibility of generalizing the results. Few results in this study are contradictory with literature which might be due to the reason that there exist many factors which affect students' satisfaction such as socio-economic status, culture and religion (Amole, 2009) which are not taken into consideration in this study. Another very important limitation is the cross-sectional design of the study which does not allow us to make inference about the causality path. Therefore future research should be carried out with longitudinal studies.

\section{References and notes:}

AlKandari, N. (2007). Students' perceptions of the residence hall living environment at Kuwait University. College Student Journal, 41(2), 327-335.

Amole, D. (2005). Coping strategies for living in student residential facilities in Nigeria. Environment and Behaviour, 37, 201-219.

Amole, D. (2009). Residential satisfaction in students' housing. Journal of Environmental Psychology, 29, 76-85.

Astin, A. W. (1993). What matters in college? Four critical years revisited. San Francisco: Jossey- Bass.

Bandura, A. (1997). Self-efficacy: The exercise of control. New York: W.H. Freeman and Company.

Bandura, A. (Ed.) (1995). Self-efficacy in changing societies. New York: Cambridge University Press.

Ballou, R., Reavill, L., \& Schultz, B. (1995). Assessing the immediate and residual effects of the residence hall experience: Validating Pace's 1990 study of on-campus and off campus students. Journal of College and University Student Housing, 25, 16-21.

Bean, J. P., \& Bradley, R. K. (1986). Untangling the Satisfaction-Performance Relationship for College Students. Journal of Higher Education, 57(04), 393-412.

Beedie, A., \& Kennedy P. (2002). Quality of social support predicts hopelessness and depression post spinal cord injury. Journal of Clinical Psychology in Medical Settings, 9(3), 227-234.

Centra, J. A., \& Rock, D. (1983). College Environments and Student Achievement. American Educational Research Journal, 08, 623-634. 
Cohen, S., Kamarck, T., \& Mermelstein, R. (1983). A global measure of perceived stress. Journal of Health and Social Behavior, 24, 385-396.

Collins, N. L., \& Feeney, B. C. (2004) Working models of attachment shape perceptions of social support: Evidence from experimental and observational studies. Journal of Personality and Social Psychology, 87, 363-383.

Daugherty, T. K., \& Lane, E. J. (1999). A longitudinal study of academic and social predictors of college attrition. Social Behavior and Personality, 27 (4), 355-362.

Dodgson, P. G. \& Wood, J. V. (1998) Self-esteem and the cognitive accessibility of strengths and weaknesses after failure. Journal of Personality and Social Psychology $75(1), 178-197$.

Dunn, A. (2001). Into the unknown. Education Age, (March7, 2001). 16.

Elliot, K.M., \& Healy, M.A. (2001).Key factors influencing student satisfaction related to recruitment and retention. Journal of Marketing for Higher Education, 10(4), 1-11.

Fay, G. (1981). A model for reviewing growth environments. Journal of College and University Student Housing, 11(1), 46-7.

Foubert, J. D., Tepper, R., \& Morrison, D. R. (1998). Predictors of student satisfaction in university residence halls. Journal of College and University Student Housing, 2l(1), 41-6.

Gottlieb, B. H. (1983). Social support strategies. Beverly Hills, CA: Sage.

Hassanain, M. A. (2008). On the performance evaluation of sustainable student housing facilities. Journal of Facilities Management, 6 (3), 212-25.

Helgesen, O., \& Nesset, E. (2007). What accounts for students' loyalty? Some field study evidence. International Journal of Educational Management, 21 (2), 126-143.

Jou, Y. H., \& Fukada, H. (1996). The causes and influence of transitional stress among Chinese students in Japan. Journal of Social Psychology, 136(4), 501-509.

Karlin, R. A., Rosen, L. S., \& Epstein, Y. M. (1979). Three Into Two Doesn't Go: A Follow-up on the Effects of Overcrowded Dormitory Rooms. Personality and Social Psychology Bulletin, 5(3), 391-395.

Kaya, N., \& Erkip, F. (2001). Satisfaction in a Dormitory Building: The Effects of Floor on the Perception of Room Size and Crowding. Environment and Behaviour, 33(1), 3553.

Khozaei, F., Ayub, N., Hassan, A. S., \& Khozaei, Z. (2010). The Factors Predicting Students' Satisfaction with University Hostels, Case Study, Universiti Sains Malaysia. Asian Culture and History, 2 (2).

Kotler, P., Lane, K. K., Koshy, A., \& Jha, M. (2009). Marketing Management - A South Asian Perspective: Pearson Publication.

Lane, A. M., Jones, L., \& Stevens, M. (2002). Coping with failure: The effects of selfesteem and coping on changes in self-efficacy. Journal of Sport Behavior, 25(4), 331-345.

Lazarus, R. S., \& Folkman, S. (1984). Stress, Appraisal, and Coping. Springer Publishing Co, New York.

Li, Y., Mack C. Sheely, I., \& Whalen, D. F. (2005). Contributors to Residence Hall Student Retention: Why do Students Choose to Leave or Stay? Journal of college and University student housing 33(2).

Lindley, L. D., \& Borgen, F. H. (2002). Generalized self-efficacy, Holland theme selfefficacy, and academic performance. Journal of Career Assessment 10(3), 301-314.

Miville, M. L., \& Constantine, M. G. (2006). Sociocultural predictors of psychological help-seeking attitudes and behavior among Mexican American college students. Cultural Diversity and Ethnic Minority Psychology, 12(3), 420-432. 
Mohit, M. A., Ibrahim, M., \& Rashid, Y. R. (2010). Assessment of residential satisfaction in newly designed public low-cost housing in Kuala Lumpur, Malaysia. Habitat International, 34(1), 18-27.

Moos, R., \& Lee, E. (1979). Comparing residence hall and independent living settings. Research in Higher Education, 1(3).

Multon, K. D., Brown, S. D., \& Lent, R. W. (1991). Relation of self-efficacy beliefs to academic outcomes: A meta-analytic investigation. Journal of Counseling Psychology, 38(1), 30-38.

Nelson, N. G., Dell'Oliver, C., Koch, C., \& Buckler, R. (2001). Stress, coping, and success among graduate students in clinical psychology. Psychol Rep. 88(3 Pt 1), 759-67.

Najib, N. U. M., \& Abidin, N. Z. (2011). Student residential satisfaction in research universities. Journal of Facilities Management, 9(3), 200-212.

Oliver, R. L. (1997). Satisfaction: A Behavioural Perspective on the Consumer. Irwin/McGraw Hill, New York, NY.

Pike, G. R. (1991). The Effects of Background, Coursework, and Involvement on Students'

Grade and Satisfaction. Research in Higher Education, 32(01), 15-31.

Pizam, A., \& Ellis, T. (1999). Customer satisfaction and its measurement in hospitality enterprises. International Journal of Contemporary Hospitality Management, 11 (7), 326-39.

Pritchard, M. E., \& Wilson, G. S. (2003). Using emotional and social factors to predict student success. Journal of College Student Development 44(1), 18-28.

Rodger, S. C., \& Johnson, A. M. (2005). The Impact of Residence Design on Freshman

Outcomes: Dormitories Versus Suite-style residences. The Canadian Journal of Higher Education, 35(3), 83-99.

Rosenberg, M. (1965). Society and the adolescent self-image. Princeton, NJ: Princeton University Press.

Ruprai, R. K., Kamble, P., \& Kurwale, M. (2012). Environmental stress and changes in anxiety score and reaction time: A comparative study among day scholars and hostilities in first year MBBS students. Global Journal of interdisciplinary social sciences, 1 (2), 1-3.

Sarason, I. G., \& Sarason, B. R. (Eds.). (1985). Social support: Theory, research and applications. M. Nihjoff.

Schroeder, C. C., \& Mable, P. (1994). Residence halls and the college experience: Past and present. In C. C. Schroeder, P. Mable, \& Associates (Eds.). Realizing the educational potential of residence halls (pp. 3-21). San Francisco: Jossey-Bass.

Schwarzer, R., Baßler, J., Kwiatek, P., \& Schroder, K. (1997). The Assessment of Optimistic Self-beliefs: Comparison of the German, Spanish, and Chinese Versions of the General Self-efficacy Scale. Applied psychology: an international review,46 (1), 69-88.

Schwarzer, R., \& Jerusalem, M. (1995). Generalized Self-Efficacy Scale. In J. Weinman, S. Wright, \& M. Johnston. Measures in health psychology: Auser's portfolio. Causal and control beliefs (pp. 35-37). Windsor, UK: NFER-NELSON.

Shumaker, S. A., \& Brownell, A. (1984). Toward a theory of social support: Closing conceptual gaps. Journal of social issues, 40(4), 11-36.

Struthers, C. W., Perry, R. P., \& Menec, V. H. (2000). An examination of the relationship among academic stress, coping, motivation, and performance in college. Research in Higher Education, 41(5), 581-592.

Taylor, S. E., \& Brown, J. D. (1988). Illusion and well-being: A social psychological perspective on mental health. Psychological Bulletin, 103(2), 193-210. 
Towbes, L. C., \& Cohen, L. H. (1996). Chronic stress in the lives of college students: Scale development and prospective prediction of distress. Journal of Youth and Adolescence, 25 (2), 199-217.

Wohlgemuth, E., \& Betz, N. E. (1991). Gender as a moderator of the relationships of stress and social support to physical health in college students. Journal of Counseling Psychology, 38(3), 367-374.

Wolfe, R. N., \& Johnson, S. D. (1995). Personality as a predictor of college performance. Educational and Psychological Measurement, 55, 177-185.

World Health Organization (2004). The global burden of diseases: (2008) updated. Available from http// www.who.int.

Yusoff, Y. M., \& Othman, A. K (2011). An early study on perceived social support and psychological adjustment among international students: the case of a higher learning institution in Malaysia. International Journal of Business and Society, 12 (2), 1-15.

Zajacova, A., Lynch, S. M., \& Espenshade, T. J. (2005). Self-efficacy, stress, and academic success in college. Research in higher education, 46(6), 677-706.

Zimmet, G. D., Dahlem, N. W., Simit, S. G., \& Farley, G. K. (1988). The Multidimensional Scale of Perceived Social Support. Journal of Personality Assessment, 52, 30-41. 


\title{
Summary
}

\section{Factors affecting the Academic Performance of university students residing in Student Housing Facility}

\author{
Shazia Hasan \\ University of central Punjab, Lahore Pakistan \\ Mehreen Fatima \\ COMSATS Institute of Information Technology, Lahore Pakistan
}

\begin{abstract}
Student housing facility (SHF) has been considered as an indispensable part of the facilities offered by higher education institutes today. This study is conducted to find out the impact of satisfaction generated from student housing facility and social support on their stress level, self-esteem and self-efficacy. The major focus of the study is to investigate the impact of above mentioned factors on students academic performance. Study also shows the gradual changes in these factors that come with each semester. A cross-sectional survey is conducted through questionnaires. Targeted population consists of all the girls of bachelor programs residing in Fatima Jinnah Girls Hostel of COMSATS Institute of information Technology, Lahore. A sample of 200 students is selected through systematic random sampling. Some of the results are consistent with literature while some of them show contradictory results. Further research can be conducted to investigate those results further. This study is a contribution towards literature as few studies are conducted on student housing facilities in the context of Pakistan.
\end{abstract}

Keywords: Student housing facility, gradual changes, academic performance, self-efficacy, cross-sectorial 